\title{
Scaffolding and Knowledge Appropriation in Online Collaborative Group Discussions
}

\author{
Hwee Ling Lim \\ The Petroleum Institute, Abu Dhabi, United Arab Emirates
}

\begin{abstract}
Sociocultural constructivism assumes that a learner's capacity for intellectual growth increases with the presence of scaffolding or support during interaction. Moreover, from participating in dialogic interaction, there is appropriation of the knowledge shared and jointly created by learners which could transform individual understandings. Hence, interactions are opportunities for scaffolding and appropriation that affect intellectual development. This paper presents a study of an online course based on constructivist principles and evaluates the extent to which an instructional activity, supported by synchronous communication technology in a virtual environment, fosters collaborative learning. Survey findings on two student groups' experiences of collaborative learning during online tutorials are presented. The results indicated that scaffolding was available as peers' efforts in provision and clarification of ideas during tutorial discussions. Also, appropriation of shared knowledge was present as students' perceptions of own attainment of learning from peer contributions during discussions. The conclusion discusses the effectiveness of the instructional activity in facilitating collaborative learning and offers recommendations for future research.
\end{abstract}

Keywords: Collaborative learning; Computer-mediated communication; Educational technology; Sociocultural constructivism; Virtual learning environment.

\section{Introduction}

From the sociocultural constructivist point of view, learning is an active process involving individual interpretations of experiences, the sharing of perspectives among learners, negotiation of meaning, and joint knowledge construction through dialog in authentic contexts (Vygotsky, 1962). Through such conversational interactions, learners appropriate the jointly constructed knowledge that could change their own understandings. Constructivism also assumes that a learner's capacity for intellectual growth is enhanced with the availability of scaffolding or guidance in the interactions. Hence, constructivist-based learning environments are settings that reflect the conversational paradigm (Laurillard, 2002) and emphasize collaborative effort in the knowledge building process.

This paper presents a case study of an online undergraduate course framed by constructivist principles and evaluates the extent to which an instructional activity, which is supported by synchronous communication technology in a virtual classroom environment, fosters constructivist- 
collaborative learning. A web survey was conducted among students of two tutorial groups on their online learning experiences. Quantitative and qualitative results are presented on respondents' perceptions of the availability of peer scaffolding and presence of knowledge appropriation from the virtual tutorial discussions. The conclusion discusses the implications of the findings for instructional design and offers future research directions.

\section{Background}

\section{Sociocultural Constructivism and Constructs}

Within the constructivist paradigm, there are divergent perspectives on learning held by two schools of thought: radical and sociocultural constructivism. Both approaches acknowledge that learning involves individual cognitive activity and social interaction but they differ in the emphasis placed on the primacy of each element's contribution to the learning process. The radical constructivist school of thought (von Glasersfeld, 1997) regards individual cognitive selforganization as the main process in learning. However, sociocultural constructivism (Vygotsky, 1962) emphasizes the social element in knowledge building and holds the assumption that guided participation in shared knowledge construction, mediated by technical and/or psychological tools, provides learners with scaffolding or support that enables higher potentiality of individual cognitive growth.

More specifically, the construct of the zone of proximal development (ZPD) is used by sociocultural constructivist theorists to explain the learner's potential capacity for intellectual growth when given scaffolding in the form of tutor and/or peer support through interactions that are mediated by technology and language. As explained in Wertsch (1985), the ZPD construct was developed by Vygotsky partly due to his concern over the narrow focus in educational psychology, at that time, on assessment methods that measured mostly the child's existing intellectual capability rather than provided insight on the impact of interaction on potential intellectual development. The ZPD is defined as "the distance between a child's 'actual developmental level as determined by independent problem solving' and the higher level of 'potential development as determined through problem solving under adult guidance or in collaboration with more capable peers" (Vygotsky, 1978, p.8 in Wertsch, 1985, pp.67-68). Hence, during learning, the tutor/expert peer establishes a facilitator relationship with learners for the provision of guidance when necessary that supports gradual attainment of learner control over own beliefs in face of multiple perspectives.

Later researchers extended the Vygotskian concepts of ZPD and scaffolding with the belief that sources of scaffolding include not only experts and peers but also the affordances of the whole learning environment (Duffy \& Cunningham, 1996). This study adopts the wider interpretations of the ZPD/scaffolding since it focuses on educational interactions among student peers, situated in a virtual learning environment and mediated by online communication technologies.

Sociocultural constructivists also assume that through participation in interaction, learners could individually appropriate the shared knowledge, which could change their own understandings. In more detail, Rogoff (1990) explained that as the learner participates in social interaction, s/he 
contributes to the development of group practices and with this access to socially constructed knowledge, there could be individual use or appropriation of that shared knowledge that would transform individual understandings. In other words, as learners take part in social exchanges, they could appropriate for their own use the resulting shared understandings which are essential for their enculturation into the learning community. Therefore, learning environments that facilitate social interactions are vital as they provide opportunities for dialog and appropriation that affect intellectual growth.

\section{Constructivist Learning Interactions: Technology Choices and Characteristics}

Research has found the availability of opportunities for interaction to be crucial in supporting student preferences for social contact that build relational ties leading to greater student satisfaction and higher quality learning outcomes (Bonk et al., 2001). In online educational contexts, the presence of interaction opportunities could also help reduce transactional distance between geographically separated learners (Moore \& Kearsley, 1996) and improve student retention rates (Carr, 2000). Hence, online courses with limited means of communication have been found to reinforce the perception that distance learning is an isolating experience or an inferior option compared to on-campus/face-to-face education (Kumar et al., 2002).

Computer-mediated communication (CMC) technologies are used to enable asynchronous and synchronous interactions between distant learners in online courses. Decisions on technology choices should reflect an understanding of the capabilities of the various modes and means of communication. According to Ngwenya et al. (2004), asynchronous online communication could start and end at any time between users in different places. It involves the occurrence of a dialog, activity, or event in a delayed-time mode through the use of software applications such as e-mail, bulletin boards, or discussion forums. Based on this communication mode, the design of online group learning activities is largely centered on the use of bulletin boards or discussion forums where the asynchronous interactions are mainly textual contributions which could be composed, sent, saved, sorted by topic, chronology, or discussion threads, and accessed anytime/anywhere.

In contrast, synchronous online communication requires communicating parties to be present at the same time for the event to take place. It involves the occurrence of a dialog, activity, or event in a real-time mode through the use of applications or services such as Voice over IP (VoIP), desktop video conferencing, and Internet Relay Chat (IRC). While video conferencing still faces constraints of bandwidth for audio/video synchronization, hardware/software costs and quality, VoIP and IRC are easily available on the Internet. Moreover, applications such as Yahoo Messenger ${ }^{\mathrm{TM}}$ or Windows Messenger ${ }^{\mathrm{TM}}$ currently offer additional communication channels to users besides text such as image and voice capability options. When supported by IRC, synchronous online communication typically occurs in chat rooms that are devoted to a particular subject or are conducted on a certain schedule.

Synchronous interaction in chat rooms are usually textual messages, composed and sent by dyads or multiple parties who are logged in at the same time. Rather than being arranged in a topical order as in the case of asynchronous postings, chat messages appear chronologically on-screen according to the sequence in which they are received by the server, at a speed matching the 
conversational pace and are prefixed by user login names which may or may not correspond to the actual names of the users (Werry, 1996). Moreover, a record or a log of the exchanges could be saved by the user or network administrator.

This paper focuses on a group instructional activity and its structure is described in more detail in the next section. The online activity takes place in chat tutorial rooms available from the Web Course Tools (WebCT ${ }^{\mathrm{TM}}$ ) learning management system (LMS). From the sociocultural constructivist perspective, the synchronous CMC medium, chat tutorial rooms and LMS have significant roles in supporting interaction by offering an 'interpretive zone' (Veerman et al., 2000) that allows learners to congregate and share views on particular topics or issues.

Most studies on computer-mediated interaction in online learning have concentrated on the use of the asynchronous mode (Booth \& Hulten, 2004; Kanuka \& Garrison, 2004) rather than the synchronous mode to enable group, peer-to-peer and student-tutor interactions (Armitt et al., 2002; Spencer \& Hiltz, 2003). The fewer studies on instructional chat could be due to factors such as a preference for cognitive learning approaches that do not regard dialog as crucial to the knowledge acquisition process, the view that chat functions as an 'adjunct' to asynchronous interaction for enhancing social and communal relations, and the characteristics of the chat medium (Mercer, 2003; Polin, 2000).

The chat medium tends to be vulnerable to technical problems involving reduction of communication bandwidth that may disrupt the synchronization of responses. Such an unexpected loss of network connection could also lead to participants missing part of the discussion when they have reconnected as the textual record of preceding exchanges would have scrolled off their screens. In addition, the chronological linearity inherent in the real-time CMC mode means that messages may not appear on participants' screens according to the logical sequence of exchanges. Furthermore the lack of visual turn-taking cues may result in the posting of multiple overlapping messages that could lead to discursive incoherence (Herring, 1999) in group discussions that could undermine the dialogic process of knowledge construction. The mainly text-based synchronous medium may also require additional skills from learners to fully participate in the discussions. In order to keep up with the rapid speed of chat discussions, participants may need to have prior experience in chat communication protocols, good typing skills, familiarity with 'Netspeak' and be proficient in the English language (Dykes \& Schwier, 2003).

However, studies have presented results contrary to the assumption that the synchronous CMC medium has a negative impact on interaction. Hancock and Dunham (2001) found no significant relationship between typing speed on task error rate, turn coordination or task completion time. Similarly, McDaniel et al. (1996) found that the synchronous CMC medium did not have an impact on task completion nor was the nature of chat discourse perceived by the participants to be confusing or incoherent. While the asynchronous mode has the capability to 'expand' time which allows extended interactions, the synchronous mode has the capability to 'contract' time which makes it particularly appropriate for instructional activities that require interactivity, spontaneity, and fast decision-making. The synchronous mode also provides a sense of immediacy and communicative presence hence motivating involvement in interactions that offer intellectual and emotional support to distant learning groups (Haythornthwaite et al., 2000). Moreover, Crook and Light (2002) contended that the synchronous CMC medium could support features in an online 
instructional environment that are familiar to learners and faculty, hence facilitating the transition from traditional face-to-face to online learning contexts. Since established learning practices for most communities are largely rooted in face-to-face conversational exchanges, the synchronous mode, with its close resemblance to the structure and rhythm of everyday 'talk', could facilitate the transfer of formal patterns of behavior acquired in physical classrooms to virtual classrooms.

Even as asynchronous and synchronous communication technologies can facilitate interaction between distant students, the use of such technical tools should be based on a sound theoretical framework and an understanding of their capabilities in enhancing the learning process. As stated by Edwards (2002), the available technology presents only a precondition for knowledge construction and does not represent it. To further current understanding of the integration of constructivist learning theory and technology choice, the next section describes an online undergraduate course that constituted this case study and the influence of constructivist principles on the structure of its tutorial activity design.

\section{Design of Online Course and Chat Tutorial Activity}

Organizational Informatics (OI) is an undergraduate course offered by the School of Information Technology at Murdoch University (Perth, Australia). A more detailed description of the course is available in Lim and Sudweeks (2008). The course focuses on the area of computer-mediated work processes. It aims to develop skills associated with the management of knowledge building organizations and the organizational aspects of information systems development. The Ol course has a blended delivery design, offering face-to-face lectures and online tutorials to internal and external students who, respectively, undergo the course on-campus or via distant learning. To reduce transactional distance, there is significant use of $\mathrm{WebCT}^{\mathrm{TM}}$ as a virtual learning environment (VLE) where students could access synchronous and asynchronous CMC technologies (such as email, bulletin boards, forums, chat), as well as electronic course content resources for their educational needs.

Since the external students lack face-to-face interactional opportunities with tutors and peers, a main learning activity in the course is the online synchronous (chat) tutorial discussions. The online synchronous tutorials are held in $\mathrm{WebCT}^{\mathrm{TM}}$ chat rooms and the maximum size of each tutorial group is set at 16 students with a tutor for each group. The tutorial activity aims to introduce students to the theory and application of computer-mediated work processes, and to develop collaborative group knowledge building through active participation and reflection on learning.

The weekly one-hour chat tutorials are virtual seminars, with a tutor-facilitator and two student presenters moderating the discussion. The presenter role is rotated among all students in each tutorial group. In more detail, presenters moderate a $1 / 2$ hour discussion slot each in the one-hour tutorial session based on their critiques of the week's readings. The presenter starts the discussion by highlighting main issues in the readings, moderates and extends the discussion with questions, and encourages participation by all. The other students are expected to read the presenters' critiques posted in the group's bulletin board before the tutorial, participate actively in discussions, and reflectively evaluate the presenter with the aid of the archived discussion logs. The tutor-facilitator assesses the presenter's performance, quality of contribution and extent of 
collaborative effort displayed by all. Consistent with the course's constructivist orientation, the tutorial activity design involves guided interaction, peer/tutor scaffolding of learning, dialogic exchange of different perspectives, and student reflection on learning.

\section{The Method}

\section{Web Survey Instrument}

Conventional survey methods for examining social attitudes, behavior, and group interactional processes include face-to-face interviews, telephone interviews, postal and fax surveys. The advent of web/CMC technologies led to new online survey methods such as e-mail and web surveys which are increasingly used to gather data in educational research. This study used a web survey method to gather information on students' experiences of chat tutorial interaction in terms of the adequacy of peer learning support and attainment of learning from peer/own contributions to the tutorial discussions.

The instrument was a non-anonymous web survey (Figure 1) created with Remark Web Survey ${ }^{\circledR}$ (Principia Products, 2000). The questionnaire included open-ended and closed questions on various aspects of the chat tutorial experience and participants' demographic profile. Both openended and closed questions were used for the following purposes:

- $\quad$ reduce methodological weaknesses inherent in the use of only one question type;

- capture self-reported information at varying depths; and

- enable variations in the amount of direction in answering questions. Such varying opportunities for self-expression and qualification may serve to enhance both relevance of the survey and respondent interest (Payne, 1951, 2004).

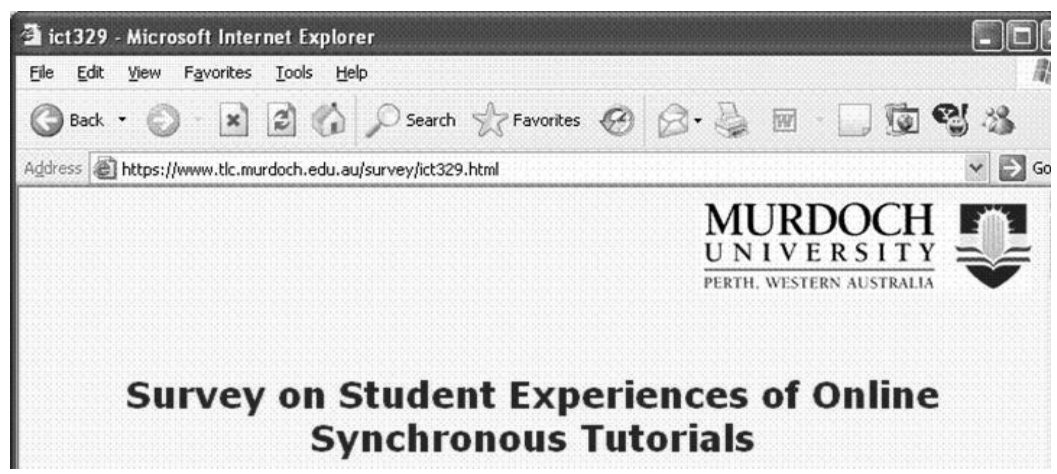

Figure 1. Web survey instrument

In data analysis, the responses to closed questions were pre-coded by the survey software and descriptive statistical analysis was applied while responses to open-ended questions were postcoded using categories that emerged from content analysis of the responses. 


\section{Issues of Validity}

The use of self-reported data is not without its problems but the validity of self-reports is generally held to be supported under certain conditions (Aaker et al., 2004):

- the survey questions are unambiguous, refer to recent activities, and do not intrude into private matters or require socially desirable responses;

- respondents have the knowledge, opinion, attitudes required;

- $\quad$ respondents are willing and able to respond; and

- respondents hold the view that the questions deserve a thoughtful response.

Although the validity of self-reports in the context of educational research has been recognized (Chesebro \& McCroskey, 2000), this study acknowledges areas of vulnerability in the use of such data and describes the practices undertaken to enhance validity of self-reported data obtained. While external validity, as generalizability of the survey findings, does not apply in this single case study, internal validity is relevant in terms of content and construct validity of the survey.

The closed questions included itemized categories that are mainly statements related to interactional behavior during tutorials. Hence, there is a need to ensure content validity in the sense that the statements reflect accurately the events occurring during the tutorials. Kahn and Cannell $(1957,2004)$ held that establishing common frames of reference could reduce ambiguity in question interpretation and enhance perception of question relevance to the context of respondents' own experiences. This was achieved by explicitly incorporating references to the chat tutorial context in the question statements; for example, through the use of phrases "online tutorial in this unit" and "during the discussion" in Q.3 (Figure 2) and Q.5g-i (Figure 3). As verbal clarification by the researcher would not be possible for self-administered questionnaires, clarity of language and expression had to be ensured. For instance, the term "online tutorials" was not considered unfamiliar since it was used often in course documents and during tutorial discussions.

At a higher level, there is a need to ensure construct validity of instrument as the appropriateness of the survey questions for eliciting the required information. Closed questions are particularly vulnerable to measurement error as error of central tendency manifested in the consistent selection of neutral/mid points in rating scales (for example, Unable to Judge, Don't Know, No Opinion) by respondents due to the establishment of a comfortable pattern reinforced by an unvarying response format (Herzog \& Bachman, 1981). This was reduced with the provision of an Unable to Judge (UJ) option only in one question (Q.5, see Figure 3 ).

3. How much help was available from your tutor and other students during online tutorials? Indicate your responses to the following statements from Strongly Agree to Strongly Disagree

b. The other students clarified issues on content that were raised during the discussion

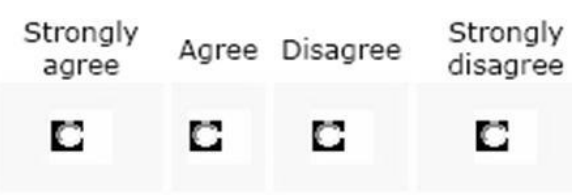

Figure 2. Question 3b 
Open-ended questions are often used to obtain elaborations to responses in earlier questions and gather responses that could not be foreseen. Such verbatim responses constitute rich descriptions that add to the credibility of the findings by qualitative research standards (Denzin \& Lincoln, 2005). For example, since Q.3b and Q.5g were closed questions that covered perceptions of participation patterns in online tutorials, two open-ended questions (Q.6/Q.7) were included to prompt further explanations on the factors that motivated and inhibited contributions to discussions (Figure 4). Moreover, as Q.5 had an UJ option, an open-ended question was included to capture the respondents' reasons for indicating difficulties in judging their experiences of tutorial discussions (Figure 5).

5. To what extent do the following statements accurately reflect your overall experience of online tutorials in this unit? Indicate your responses to the following statements from Strongly Agree to Strongly Disagree or Unable to Judge (UJ ).

g. The other students contributed different ideas to the discussion

Strongly Agree Disagree $\begin{gathered}\text { Strongly Unable } \\ \text { agree }\end{gathered}$ disagree to judge
agree

h. I learned from other students' contributions during the discussion

i. I helped other students learn through my contributions during the discussion

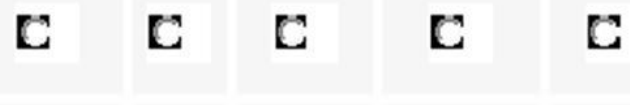

Figure 3. Question 5g-i

6. Were there other factors that encouraged or motivated you to contribute during tutorial discussions in this unit? Please describe them below.

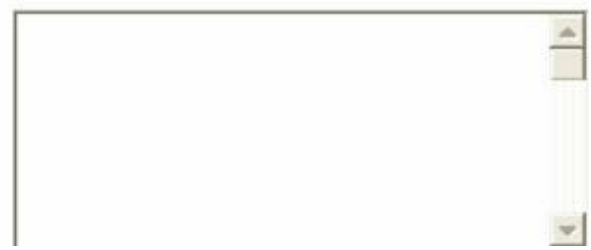

7. Were there other factors that discouraged or inhibited you from contributing during tutorial discussions in this unit? Please describe them below.

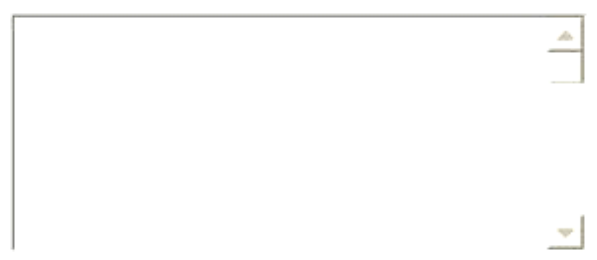

Figure 4. Questions 6 and 7: Open-ended Questions 
If you were unable to rate any of the above factors (i.e. selected Unable to Judge), why is this so? Please explain below.

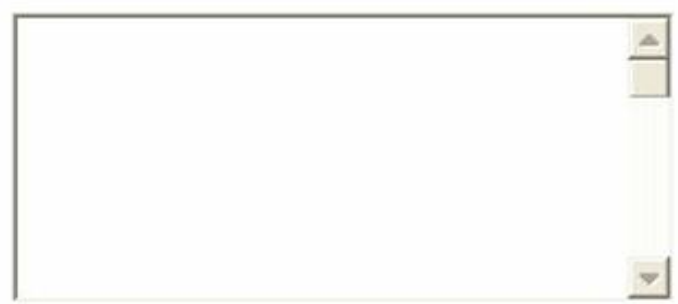

Figure 5. Open-ended Question in Question 5

Both issues of content and construct validity were addressed the pre-test and refinement stages of the survey development process, with modifications made (questions were added, discarded, rephrased or re-ordered) that improved question clarity, sequence and layout. Pre-testing was conducted to identify areas of deficiencies and feedback from this stage confirmed relevance of the statements to the actual experiences of respondents. The actual survey was administered in the last week of the course so as to best capture participants' recollection of recent events.

\section{The Sample and Ethical Considerations}

The survey was administered to 23 students from two chat tutorial groups (Table 1) with return rates of 93\% (Group $1=13$ returns) and 89\% (Group $4=8$ returns). Both G1 and G4 had different tutors but were involved in equivalent learning activities covering the same topics.

Table 1. Tutorial groups 1 and 4

\begin{tabular}{lll}
\hline Characteristics & Group 1 & Group 4 \\
\hline Group size & -15 students, 1 tutor & -9 students, 1 tutor \\
\hline Enrolment status & -13 Internal, 2 External students & -4 Internal, 5 External students \\
\hline Nationality & - Majority international students, & - Majority Australian students, \\
& minority Australian students & minority international students \\
\hline Gender & -3 females and 12 males & -1 female and 8 males \\
\hline
\end{tabular}

Since the survey was non-anonymous, confidentiality of participant identity was maintained by replacing the participants' actual names with pseudonyms in the data processing stage. Particular care was taken to ensure that actual names that appear in responses to open-ended questions were replaced by respective pseudonyms.

\section{Findings}

The constructivist framework of the course assumes that effective learning activity design provides opportunities for scaffolding that enables the appropriation of constructed knowledge. Hence, it is 
essential to evaluate the extent to which the chat tutorial activity fosters collaborative learning processes. A subset of results from Lim (2006) are presented here on student experiences of peer scaffolding defined as the extent of learning support perceived to be available from other students on providing different ideas and clarifying content issues during tutorial discussions; and appropriation of shared knowledge defined as the attainment of learning from contributions to discussions.

\section{Demographics of Participants}

Demographic data from the survey (Table 2) showed that G1 and G4 participants had various cultural backgrounds, with different English language (EL) proficiency levels and experience in using the synchronous CMC medium. G4 participants were all native EL speakers while G1 included both native and English as a Foreign/Second Language (ESL/EFL) speakers. There were also group level differences in experience with chat media prior to attending the online tutorials. All G4 participants had used chat at least monthly compared to $77 \%$ of G1 participants. Moreover, $23 \%$ of G1 participants had hardly ever/never used the chat media. These differences provide valuable insight into the group learning processes but do not preclude comparative group analysis since both groups were involved in equivalent learning activities covering the same topics.

Table 2. Demographics of survey participants

\begin{tabular}{|c|c|c|}
\hline Characteristics & Group 1 Participants & Group 4 Participants \\
\hline $\begin{array}{l}\text { English language } \\
\text { proficiency }\end{array}$ & $\begin{array}{l}\text { - } 5 \text { ESL/EFL speakers } \\
-8 \text { native English language speakers }\end{array}$ & - 8 native English language speakers \\
\hline $\begin{array}{l}\text { Cultural } \\
\text { background }\end{array}$ & $\begin{array}{l}\text { - a mix of African, Asian and Caucasian } \\
\text { students }\end{array}$ & $\begin{array}{l}\text { - a mix of Asian and Caucasian } \\
\text { students }\end{array}$ \\
\hline $\begin{array}{l}\text { Prior chat } \\
\text { experience }\end{array}$ & $\begin{array}{l}\text { - } 10 \text { students used chat media at least } \\
\text { monthly } \\
\text { - } 3 \text { student hardly ever/never used the } \\
\text { chat media }\end{array}$ & $\begin{array}{l}\text { - } 8 \text { students used chat media at } \\
\text { least monthly }\end{array}$ \\
\hline
\end{tabular}

\section{Availability of Peer Scaffolding}

Peer scaffolding was measured by two questions (Q.3b/Q.5g) on the availability of different ideas and clarification of content issues from other students in the tutorial group. The respondents indicated their extent of agreement on a 4 or 5 point Likert-like scale from Strongly Agree (SA) to Strongly Disagree (SD), with an Unable to Judge (UJ) option for Q.5g (Table 3).

Although most respondents agreed that other students participated in contributing and clarifying ideas during tutorial discussions, a between group comparison found greater agreement (SA\&A) among G4 respondents (100\%) on the availability of different ideas and clarification from peers compared to $\mathrm{G} 1(84.6 \%)$. 
Table 3. Extent of peer scaffolding

\begin{tabular}{lllllll}
\hline Questions & Group & SA & $A^{*}$ & $D^{*}$ & SD* & UJ* \\
\hline $\begin{array}{l}\text { Q.3b. The other students clarified } \\
\text { issues on content that were raised } \\
\text { during the discussion }\end{array}$ & $\mathrm{G} 1$ & $15.4 \%$ & $69.2 \%$ & $15.4 \%$ & $0.0 \%$ & $-* *$ \\
\cline { 2 - 7 } & $\mathrm{G} 4$ & $50.0 \%$ & $50.0 \%$ & $0.0 \%$ & $0.0 \%$ & $-* *$ \\
\hline $\begin{array}{l}\text { Q.5g. The other students contributed } \\
\text { different ideas to the discussion }\end{array}$ & $\mathrm{G} 1$ & $15.4 \%$ & $69.2 \%$ & $15.4 \%$ & $0.0 \%$ & $0.0 \%$ \\
\cline { 2 - 7 } & $\mathrm{G} 4$ & $37.5 \%$ & $62.5 \%$ & $0.0 \%$ & $0.0 \%$ & $0.0 \%$
\end{tabular}

* $S A=$ strongly agree; $A=$ agree; $D=$ disagree; $S D=$ strongly disagree; $U J=$ unable to judge.

**The UJ option was not available for Q.3b.

Content analysis of the responses to the open-ended questions (Q.6/Q.7, see Figure 4) revealed two main factors that affected contributions to discussions: the synchronous CMC medium and the quality of online interaction.

The synchronous mode of the online tutorials was singled out by some respondents as motivating participation for the following reasons:

The main factor $i$ think that because it was not face-to-face $i$ felt abit more at ease at putting forward my opinions. I am quite a shy person and at times i think that my ideas are wrong or not correct, so at times abit hesitant to put them forward. The tutorial being online really did help. Gave me more confidence. [Scott]

However, technical problems and the synchronicity of the medium proved difficult for other respondents.

...technical issues like browsers, connection speed (delay in messages). [Alan]

At times I found that I had a lot of things to say, but by the time I had thought of how to word my comments appropriately and typed them, the discussion had moved on. As I didn't want to refer back to a previous part of the discussion, my comments were deleted before being posted. This is similar to what would happen in face-to-face communications, but seemed to either occur more often, or become more noticeable when it happened. [Jack]

Additionally, the quality of online interaction among participants, characterized by the sharing of multiple perspectives, was regarded as a motivating factor for contributing to discussions.

Well I guess what encouraged me... was that everyone in the tutorial group was open and accepting of other ideas and feelings. They were all willing to listen. [Robin] 


\section{Appropriation of Shared Knowledge}

The appropriation of shared knowledge was measured by two questions (Q.5h/i) on participants' perception of attainment of learning from peer/own contributions to tutorial discussions. The respondents indicated their extent of agreement on the same scale described earlier.

Table 4 shows;

- all G4 respondents reported that they learnt from peers' contributions compared to $92.3 \%$ in $\mathrm{G} 1$.

- a small difference in the percentage of respondents from both groups who reported that other students learnt from their contributions to tutorial discussions ( $G 4=50 \% ; \mathrm{G} 1=53.9 \%$ ).

- approximately half the respondents in both groups Disagreed and were Unable to Judge that peers had learnt from their contributions to tutorial discussions.

Table 4. Appropriation of shared knowledge

\begin{tabular}{lllllll}
\hline Questions & Group & $S A^{*}$ & $A^{*}$ & $D^{*}$ & $S D^{*}$ & $U^{*}$ \\
\hline $\begin{array}{l}\text { Q.5h. I learned from other students' } \\
\text { contributions during the discussion }\end{array}$ & $\mathrm{G} 1$ & $30.8 \%$ & $61.5 \%$ & $7.7 \%$ & $0.0 \%$ & $0.0 \%$ \\
\cline { 2 - 7 } & $\mathrm{G} 4$ & $37.5 \%$ & $62.5 \%$ & $0.0 \%$ & $0.0 \%$ & $0.0 \%$ \\
\hline $\begin{array}{l}\text { Q.5i. I helped other students learn } \\
\text { through my contributions during the } \\
\text { discussion }\end{array}$ & $\mathrm{G} 1$ & $7.7 \%$ & $46.2 \%$ & $23.1 \%$ & $0.0 \%$ & $23.1 \%$ \\
\cline { 2 - 7 } & $\mathrm{G} 4$ & $12.5 \%$ & $37.5 \%$ & $25.0 \%$ & $0.0 \%$ & $25.0 \%$ \\
\hline
\end{tabular}

*SA=strongly agree; $A=$ agree; $D=$ disagree; $S D=$ strongly disagree; $U J=$ unable to judge.

There were respondents from both groups who selected the UJ option hence indicating difficulties in judging attainment of learning by others which they explained below.

I have not heard any comments from other students about them having learnt from my contributions. [Diane]

Sometimes I contributed more, sometimes didn't. Am not sure whether other students can learn through my contributions. [Wendy]

Overall, compared to G1, there was stronger perception by G4 regarding the availability of peer support in terms of efforts in provision, clarification of points, and mutual exchange of ideas during discussions. There were smaller differences between groups regarding own attainment of learning from peer contributions. However, there were equivocal findings on perception of others' achievement of learning which were attributed by some respondents to the lack of peer feedback.

\section{Discussion and Conclusion}

From the sociocultural constructivist perspective, virtual learning environments that integrate constructivist theory and technology tools could facilitate interactions that enable scaffolding and 
lead to knowledge appropriation. This paper described an online undergraduate course framed by constructivist principles and evaluated the extent to which the course tutorial activity, held in a virtual classroom environment and supported by chat technology, fosters the collaborative learning process. A web survey was administered to two student groups that gathered results on the availability of peer scaffolding and presence of knowledge appropriation from the chat tutorial discussions.

The quantitative results from comparative group analysis showed that peer scaffolding was available, but at varying extent, as efforts by other students to participate in providing and clarifying ideas during tutorial discussions. In other words, even as there was peer support in both tutorial groups, a greater degree of collaborative peer learning was perceived to be present in G4 compared to G1. This result may be explained by the factors of group size and participant characteristics. Since the groups differed in size, with G1 (15 students) being larger than G4 (9 students), it may have enabled more G1 participants to lurk, reduce their online 'visibility' and hence be 'free-riders' in the group (Jones, 1984). Consistent with the literature, qualitative comments from the respondents indicated that the synchronous $\mathrm{CMC}$ medium was a main factor affecting participation in discussions. Similar to the findings in Dykes and Schwier (2003), the mainly text-based synchronous CMC medium may have require additional English language and IT skills from learners to fully contribute to the fast-paced discussions. The qualitative findings were supported by the demographic data which showed that in contrast to G4, more G1 participants were non-native English speakers and without experience of using chat prior to attending the online tutorials.

Interestingly, the text-based characteristics of the synchronous CMC medium were also perceived by respondents to be part and parcel of the appeal of the synchronous $\mathrm{CMC}$ mode. Qualitative comments from the survey indicated that participation in tutorial discussions was motivated by the online nature of the interactions which gave shy students greater confidence in contributing their views. This result is consistent with the findings in Siegel et al. (1986) whereby the appearance screening capability of the text-based CMC actually encourages self-expression that leads to greater participation in learning discussions.

Although this study does not aim to determine the exact form of knowledge constructed, the attainment of learning perceived by respondents was examined to establish if there was appropriation of shared knowledge during the online learning process. Most respondents from both groups reported their own attainment of learning from peers' contributions during discussions. However, the results were less clear-cut regarding mutual attainment of learning since half the respondents in both groups disagreed or were unable to judge whether their peers had learnt from their contributions. Since, the UJ option was offered in only one set of questions (Q.5), the results are not likely to be due to errors of central tendency from instrument design. Qualitative comments from the respondents suggested that the difficulty in accurately judging others' attainment of learning could be due to the lack of peer feedback.

Essentially, findings from this study showed that the constructivist based virtual tutorial activity that is supported by chat technology could enable peer scaffolding and knowledge appropriation. However, the differences and difficulties in experiences reported offer certain possibilities for modifying the learning activity and future research. Currently, the reflective peer assessments of 
presenters (on their management and contribution to discussion) are submitted to the tutor at the end of the semester. It is recommended that such peer evaluations be disseminated more widely, to other tutorial group members. The availability of peer feedback, in a timelier manner, may raise individual student's awareness of the impact of one's own contributions on scaffolding the learning processes of others.

Within the constructive framework, it is assumed that tutor/expert-peer scaffolding has a vital role in supporting the initial stages of the learning process but the students are expected to gradually assume greater responsibility or control of their own learning. Future researchers could extend this study to compare the extent of tutor and student involvement the learning process by examining patterns of participation and domination. Furthermore, since this study examined two small groups in some depth, future research could compare the student e-learning experiences to other courses that have similar settings and activities. It may also be possible to track changes in learners' perceptions of their experiences over time by surveying respondents at different stages of the course, rather than once at the end of the semester. Such future studies could increase current understanding of improving student experiences of online learning.

Although the knowledge gained from this single study cannot be generalized to broader populations, the findings and their implications for the design of constructivist instructional activities may be relevant to higher education faculty and researchers, and other professionals involved in distance learning programs.

\section{References}

Aaker, D., Kumar, V., \& Day, G. (2004). Marketing research (8th ed.). New York: John Wiley \& Sons.

Armitt, G., Slack, F., Green, S., \& Beer, M. (2002, January). The development of deep learning during a synchronous collaborative on-line course. Paper presented at the CSCL 2002. Boulder, CO.

Bonk, C. J., Daytner, K., Daytner, G., Dennen, V., \& Malikowski, S. (2001). Using web-based cases to enhance, extend, and transform pre-service teacher training: Two years in review. In C. D. Maddux \& D. LaMont Johnson (Eds.), The Web in higher education: Assessing the impact and fulfilling the potential (pp. 189-211). New York: The Haworth.

Booth, S. \& Hulten, M. (2004). Opening dimensions of variation: An empirical study of learning in a web-based discussion. In P. Goodyear, S. Banks, V. Hodgson \& D. McConnell (Eds.), Advances in research on networked learning (Vol. 4, pp. 153-174). Boston, MA: Kluwer.

Carr, S. (2000). As distance education comes of age, the challenge is keeping the students. The Chronicle of Higher Education, 46(23), 39-41.

Chesebro, J. \& McCroskey, J. (2000). The relationship between students' reports of learning and their actual recall of lecture material: A validity test. Communication Education, 49, 297-301.

Crook, C. \& Light, P. (2002). Virtual society and the cultural practice of study. In S. Woolgar (Ed.), Virtual society? Technology, cyberbole, reality. Oxford: Oxford University Press.

Denzin, N. \& Lincoln, Y. (2005). The SAGE handbook of qualitative research (3rd ed.). Thousand Oaks, CA: Sage. 
Duffy, T. \& Cunningham, D. J. (1996). Constructivism: Implications for the design and delivery of instruction. In D. H. Jonassen (Ed.), Handbook of research for educational communications and technology (pp. 170-198). New York: Simon \& Schuster Macmillan.

Dykes, M. \& Schwier, R. (2003). Content and community redux: Instructor and student Interpretations of online communication in a graduate seminar. Canadian Journal of Learning and Technology, 29(2). Retrieved 27 April 2005 from http://www.cjlt.ca/content/ vol29.2/cjlt29-2_art-4.html

Edwards, C. (2002, 26-28 March). Discourse on collaborative networked learning. Paper presented at the Networked Learning Conference 2002, University of Sheffield, England.

Hancock, J. \& Dunham, P. (2001). Language use in computer-mediated communication: The role of coordination devices. Discourse Processes, 31(1), 91-110.

Haythornthwaite, C., Kazmer, M., Robins, J., \& Shoemaker, S. (2000). Community development among distance learners: Temporal and technological dimensions. Journal of Computer Mediated Communication, 6(1). Retrieved 29 April 2005 from http://www.ascusc.org/jcmc/ vol6/issue1/haythornthwaite.html

Herring, S. (1999). Interactional coherence in CMC. Journal of Computer Mediated Communication, 4(4). Retrieved 12 October 2004 from http://www.ascusc.org/jcmc/vol4/issue4/ herring.html

Herzog, A. \& Bachman, J. (1981). Effects of questionnaire length on response quality. The Public Opinion Quarterly, 45(4), 549-559.

Jones, G. (1984). Task visibility, free riding, and shirking: Explaining the effect of structure and technology on employee behavior. Academy of Management Review, 9(4), 684-695.

Kahn, R., \& Cannell, C. (1957/2004). The formulation of questions. In M. Bulmer (Ed.), Questionnaires (Vol. 1, pp. 55-78). London: Sage.

Kanuka, H. \& Garrison, D. (2004). Cognitive presence in online learning. Journal of Computing in Higher Education, 15(2), 1-18.

Kumar, A., Kumar, P., \& Basu, S. C. (2002). Student perceptions of virtual education: An exploratory study. In M. Khosrow-Pour (Ed.), Web-based instructional learning (pp. 132141). London: IRM Press.

Laurillard, D. (2002). Rethinking university teaching: A conversational framework for the effective use of learning technologies (2nd ed.). London: RoutledgeFalmer.

Lim, H. L. (2006). Constructing learning conversations: A study of the discourse and learner experiences of online synchronous discussions (Unpublished PhD Thesis). Murdoch University, Perth, Australia.

Lim, H. L. \& Sudweeks, F. (2008). Chatting to learn: A case study on student experiences of online moderated synchronous discussions in virtual tutorials. In S. Negash, M. Whitman, A. Woszcynski, K. Hoganson \& H. Mattord (Eds.), Handbook of distance learning for real-time and asynchronous information technology education (pp. 170-191). New York: Informing Science Reference, IGI Group. 
McDaniel, S., Olson, G., \& Magee, J. (1996). Identifying and analyzing multiple threads in computer-mediated and face-to-face conversations. Paper presented at the 1996 ACM Conference on Computer Supported Cooperative Work. Boston, MA.

Mercer, D. (2003). Using synchronous communication for online social constructivist learning. Paper presented at the 2003 CADE-ACED Conference. St Johns, Newfoundland.

Moore, M. \& Kearsley, G. (1996). Distance education: A systems view. California: Wadsworth.

Ngwenya, J., Annand, D., \& Wang, E. (2004). Supporting asynchronous discussions among online learners. In T. Anderson \& F. Elloumi (Eds.), Theory and practice of online learning (pp. 319347). Canada: Athabasca University.

Payne, S. $(1951,2004)$. Who left it open? A description of the free-answer question and its demerits. In M. Bulmer (Ed.), Questionnaires (Vol. 1, pp. 131-147). London: Sage.

Polin, L. (2000, 28 April). Affordances of a VR world as a place for learning: Discourse patterns and contextualization cues framing learning experiences for adults in a real-time, text-based, virtual reality setting. Paper presented at the AERA 2000 Symposium. New Orleans, LA.

Principia Products. (2005). Remark Web Survey ${ }^{\circledR}$ (Version 2). [Computer software], Gravis.

Rogoff, B. (1990). Apprenticeship in thinking. New York: Oxford University Press.

Siegel, J., Dubrovsky, V., Kiesler, S., \& McGuire, T. (1986). Group processes in computer-mediated communication. Organizational Behavior and Human Decision Processes, 37, 157-187.

Spencer, D. \& Hiltz, S. (2003). A field study of use of synchronous chat in online courses. Paper presented at the 36th Annual Hawaii International Conference in System Sciences (HICSS 03). Big Island, Hawaii.

Veerman, A., Andriessen, J., \& Kanselaar, G. (2000). Learning through synchronous electronic discussion. Computers and Education, 34 (Third Quarter), 269-290.

von Glasersfeld, E. (1997, May). Piaget's legacy: Cognition as adaptive activity. Paper presented at the International Congress "Does Representation need Reality?" Vienna, Austria.

Vygotsky, L. (1962). Thought and language. Cambridge, MA: MIT Press. Revised and edited by A. Kozulin, 1986.

Werry, C. (1996). Linguistic and interactional features of Internet Relay Chat. In S. Herring (Ed.), Computer-mediated communication (pp. 47-64). Philadelphia, USA: John Benjamins.

Wertsch, J. (1985). Vygotsky and the social formation of mind. Cambridge, MA: Harvard University Press.

Correspondence: Hwee Ling Lim, Assistant Professor, College of Arts \& Sciences, The Petroleum Institute, P.O. Box 2533, Sas Al Nakheel Campus, Abu Dhabi, United Arab Emirates. 